\title{
BOF PRESSURE EFFECTS OVER JET PENETRATION AT CSA THYSSENKRUPP*
}

\author{
Daniel Augusto Godinho de Carvalho ${ }^{1}$ \\ Breno Totti Maia² \\ Fabrício Silveira Garajau ${ }^{3}$ \\ Marcelo de Souza Lima Guerra \\ Roberto Parreiras Tavares ${ }^{5}$
}

\begin{abstract}
Due to operational conditions and locations, BOF suffers variations in important parameters whose effects on the liquid bath are usually neglected. The present paper investigated two aspects: inner BOF pressure and oxygen temperature in the stagnant reservoir. The results have shown that oxygen temperature changes properties like density and velocity but has small influence on jet penetration. The BOF inner pressure has significant influence on jet penetration and creates a new challenge regarding nozzles dimensions considering overexpanding and underexpading jets.
\end{abstract}

Keywords: BOF Pressure; Jet Penetration; Mass movement.

M.Sc., Metallurgical Eng, CSA, Santa Cruz, RJ, Brasil;

ABM Member; Dr., Metallurgical Eng., Researcher Lumar Metals, Belo Horizonte, MG, Brasil;

ABM Member; M.Sc.,Mechanical Eng.,Researcher, Lumar Metals. Ipatinga, MG, Brasil;

ABM Member; M.Sc.,Mechanical Eng., Researcher, Lumar Metals. Ipatinga, MG, Brasil;

ABM Member; Metallurgical Eng., Professor, Departamento de Engenharia Metalúrgica e Materiais da UFMG, Belo Horizonte, MG, Brasil. 


\section{INTRODUCTION}

The concepts involved in sonic jets originate in energy conservation equations, mass conservation and state equations applied in systems at steady state. To simplify the calculations developed, oxygen is considered an ideal gas. The energy conservation equation establishes a relation between fluid velocity, change of the potential energy, energy associated with the level of pressure and work done by the fluid. A first simplified Bernoulli equation to describe the behavior of sonic jets consists in considering a horizontal tube, turbulent flow; neglecting the effects of frictional forces and finally assuming that no work is performed in the neighborhood. Besides these simplifications, for compressible fluid, the equation is differentiated in terms of the average speed, considering one-dimensional flow. From this equation, relations between velocity, pressure and density are established. These relations require the introduction of others relations to form a system of equations. SHAPIRO et al. (1988) describe the sound wave as a wave of pressure which causes a small perturbation which propagates through a gas, liquid or solid, with a speed "vs" and depends on average properties. Thus, applying the principle of mass conservation for the perturbation caused by this sound wave is possible to establish a relation between velocity and density. Through a force balance, a relation between the change in velocity with the change in pressure is established. Considering the variation in the transversal section of the duct, and combining with the previously established relations, the following equation is obtained

$\frac{d A}{A}=-\frac{d v}{\bar{v}} \times\left(1-M a^{2}\right)$

where " Ma " - dimensionless Mach number, "A" - area and " v" = Speed $\left(m \cdot \mathrm{s}^{-1}\right)$.

The dimensionless Mach number is a relation between the fluid velocity and the sound velocity at environment. Figure 1 shows the evolution of subsonic speed to supersonic in relation to area

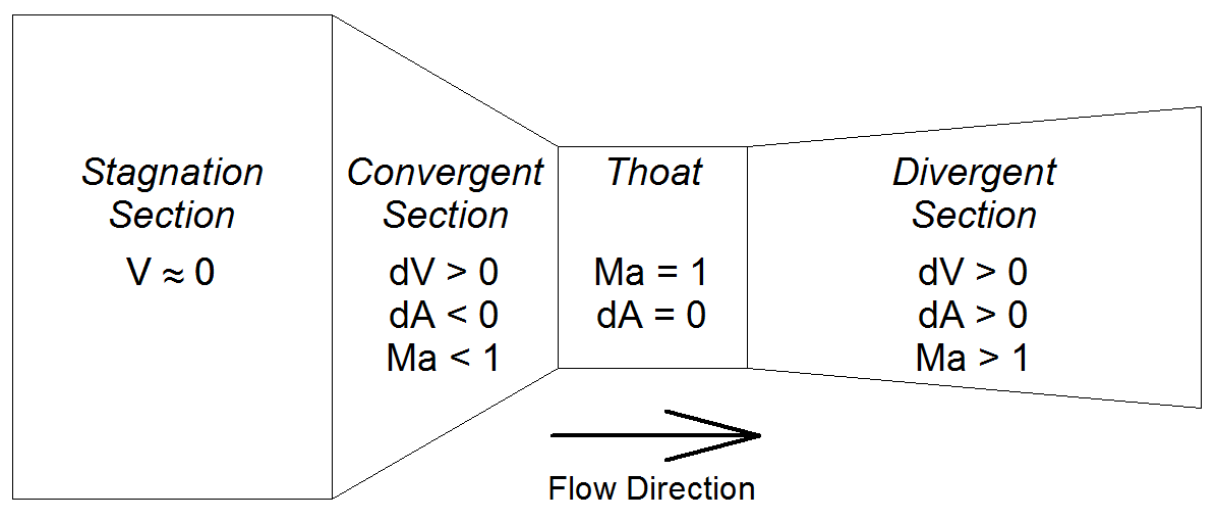

Figure 1- Inlet and outlet of a supersonic nozzle (NASCIMENTO, 2010).

The variations in the gas properties can be expressed in graphical form as a function of Mach number, as seen in Figure 2 .The development of expressions relating pressure, temperature and density of the gas is based on an energy balance in an adiabatic and isentropic process relating any two points along the duct. Changes in flow properties are gradual in all cases except when the ratio $A / A$ * is close to unity, where the flow characteristics are changed rapidly with small changes in section. The 
location around this region is called the transonic zone, since it is the transition from subsonic to supersonic regime. The calculations are long and laborious and the results represent the average values over the length of the jet axis, not being possible to evaluate the variations in the properties of the nozzle cross section.

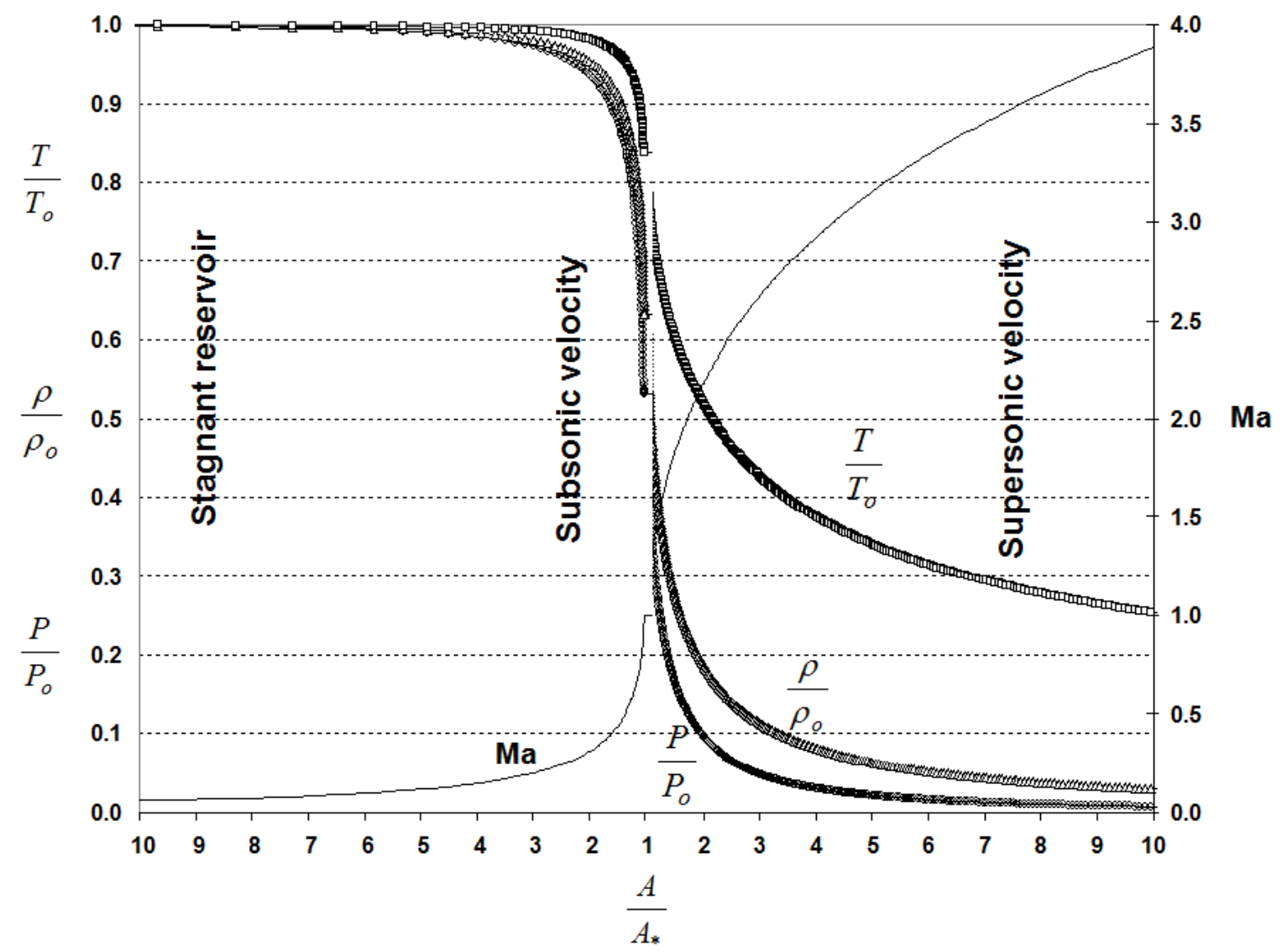

Figure 2 - Variation of flow properties with A / A variation $^{(1)}$.

\section{MATERIAL AND METHODS}

For this study, it was considered a fixed absolute pressure in the stagnant reservoir, $P_{0}=9,83 \times 10^{5} \mathrm{~Pa}$, as well as fixed dimensions for the nozzle conditions and varying ambient pressures as shown in Table I

Table I - Environment pressure conditions.

\begin{tabular}{cc}
\hline $\mathbf{P}_{\text {EXIT }} / \mathbf{P}_{\mathrm{O}(\#)}$ & Condition \\
\hline $\mathbf{P}_{\text {EXIT }} / \mathbf{P O}_{\mathbf{0}} \mathbf{0 , 1 1 0 4}$ & Environment \\
$\mathbf{P}_{\text {EXIT }} / \mathbf{P}_{\mathrm{O}}>\mathbf{0 , 1 1 0 4}$ & Over pressure environment \\
$\mathbf{P}_{\text {EXIT }} / \mathbf{P O}_{\mathbf{0}}<\mathbf{1 1 0 4}$ & Under pressure environment \\
\hline
\end{tabular}

The distance between the bath and the lance (DBL) was fixed at $2048 \mathrm{~mm}$ and the tuyère flow rate in $12 \mathrm{~m}^{3} / \mathrm{min}$, with a total for 12 tuyères, for bottom injection.

The Mach number is influenced by environmental conditions inside the converter as shown by equation (2): 
$M a=\sqrt{\left.\frac{2}{(\gamma-1)} \times\left(\frac{1}{\left(\frac{P_{B O F}}{P_{O}}\right)}\right)^{\left(\frac{\gamma-1}{\gamma}\right)}-1\right)}$

Where: "PBOF" - BOF pressure (Pa); "PO" - Stagnant reservoir pressure $(\mathrm{Pa})$; " $\gamma$ " adiabatic gas constant $\left(\mathrm{C}_{\mathrm{p}} / \mathrm{C}_{\mathrm{v}}\right)$.

Considering a fixed pressure at the stagnant reservoir and changing the pressure inside the BOF, it is possible to note that a reduction in the BOF inner pressure increases the Mach number. On the other side, for pressurized BOF's, the ratio between pressures increases. When this ratio is close to 1 , the flow rate decreases and Mach number tends to zero.

Based on an energy balance, the jet penetration was expressed as a function of the modified Froude number, according to equations developed by Szekely(3), Meidani et al, (4) , Alam et al. ${ }^{(5,6,7)}$ and Maia (8). Equation 3 presents the result of this energy balance. The variables involved in this equation are schematically shown in Figure 3.

$$
\frac{\pi \times \rho_{G A S} \times V_{E X I T}^{2} \times D_{E X I T}^{2} \times \cos \theta \times n}{4 \times \rho_{\text {LIQUID }} \times g \times H^{3}}=\frac{\pi}{2 \times K^{2}} \times \frac{P}{H}\left(1+\frac{P}{H \times \cos \theta}\right)^{2}
$$

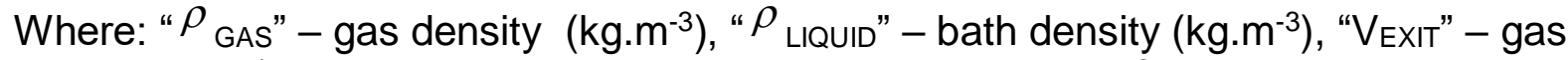
velocity $\left(m . s^{-1}\right)$, "DEXIT" - exit diameter $(m), " g$ " - gravity $\left(m \cdot s^{-2}\right)$, "P" - Penetration $(\mathrm{m})$, "H" - distance lance bath $(\mathrm{m})$, "K" - empirical factor, " $\theta$ " - tip nozzles angle, " $\mathrm{n}$ " - number of nozzles.

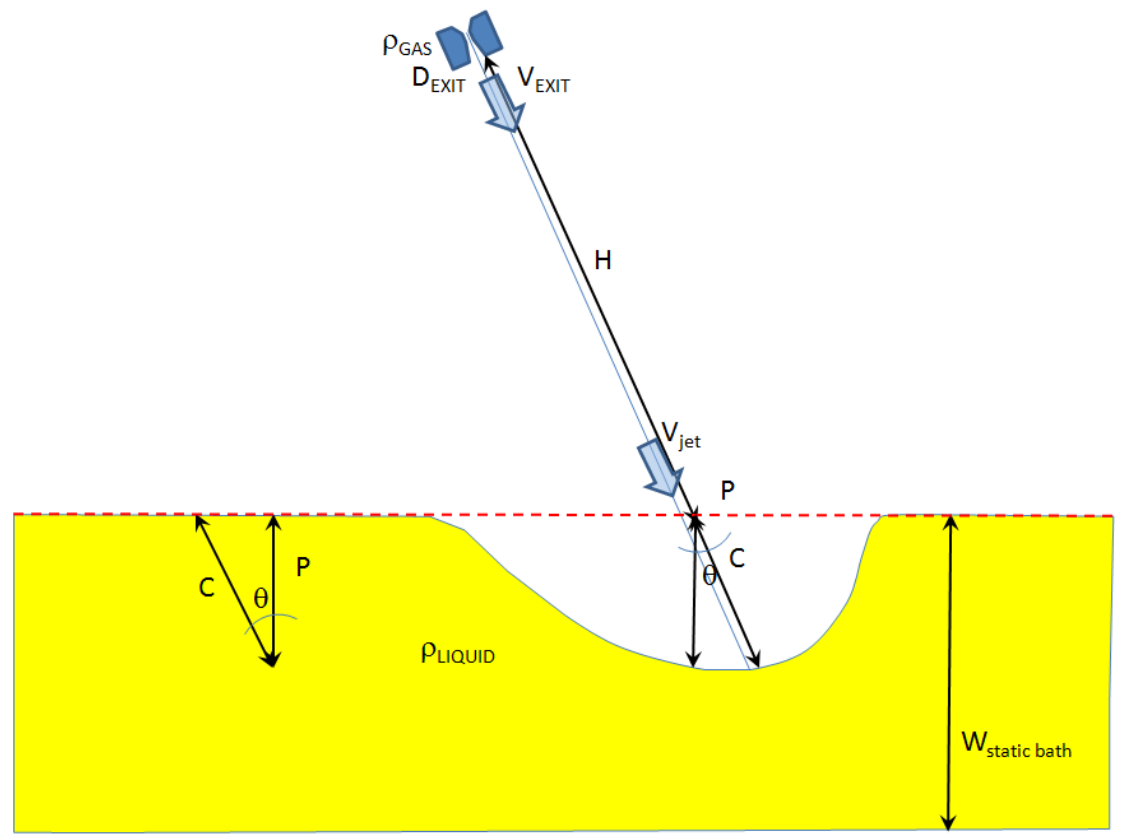

Figure 3 - Schematic draw for gas jet penetration into liquid bath. 
Considering that each nozzle creates one cavity and that its radius represents the jet penetration, it was possible to estimate the amount of mass displaced by the jet. The effects of the pressure inside the BOF on the oxygen flow rate, Mach number and amount of mass displaced by the jet were analyzed. The results are presented and discussed in the next item.

\section{RESULTS AND DISCUSSION}

Figure 4 shown pressure variations into 220t BOF over oxygen jet for fixed pressure at stagnant reservoir.

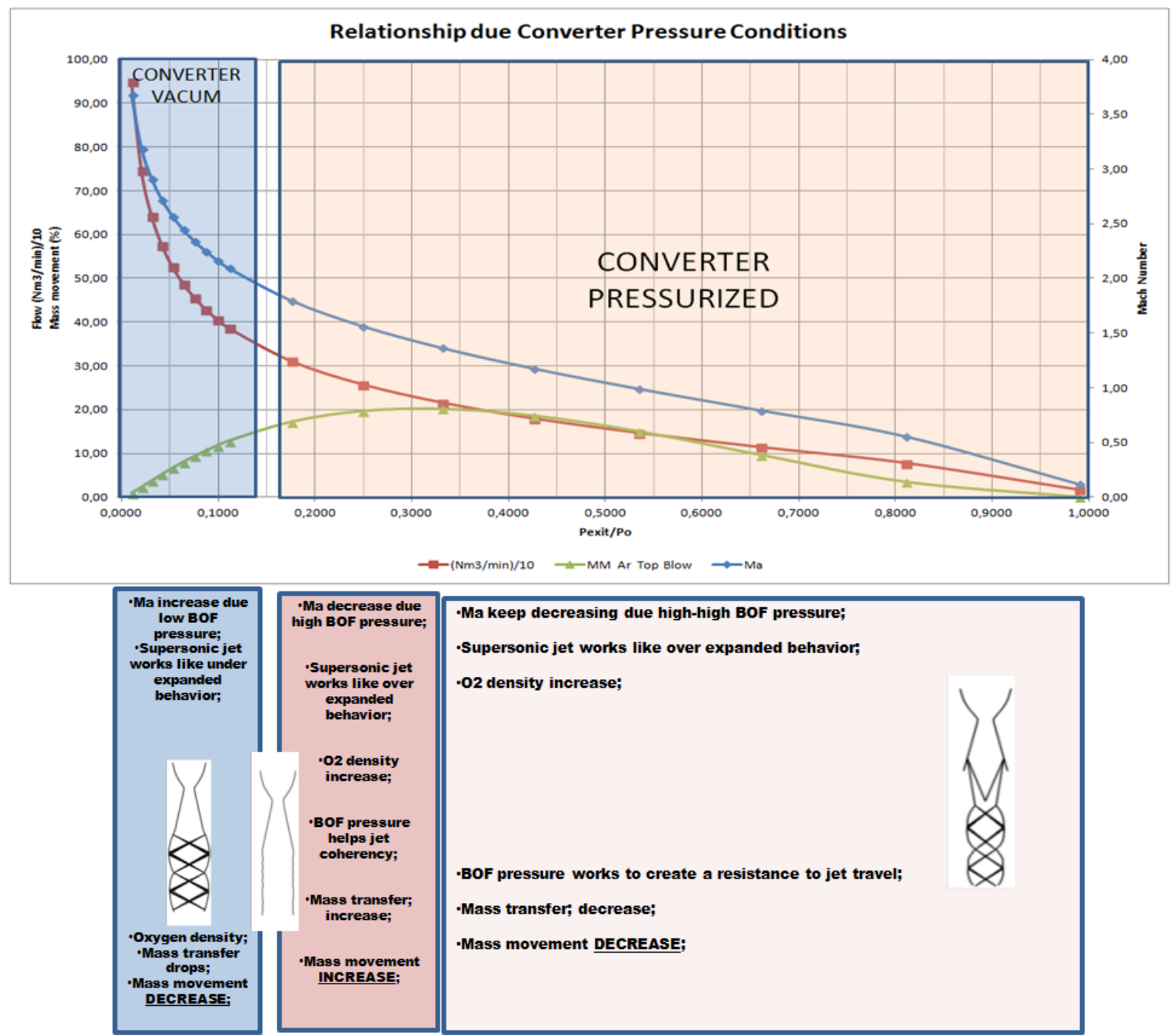

Figure 4- Oxygen jet behaviour x BOF internal pressures.

The Mach number like equation 1 is affected by relationship between stagnant reservoir pressure and environmental furnace pressure. Thus the smaller this reason, that mean, bigger difference between two different places, bigger will be the increase of Mach number. This can be interpreted with same behavior of subexpanded jets, increase volumetric expansion, that consequence will be increase the flow. However this behavior has negative effects over oxygen mass transfer rate for liquid bath for fixed distance lance bath, implied at low bath penetration. 
Considering data from 338t BOF converters, were made new calculations for this peculiar converter and conditions into oxygen stagnant reservoir. It is important comment that this converter has recovery gas system, operating with suppressed combustion system. Figure 5 shown the behavior for oxygen stagnant reservoir at $15 \mathrm{kgf} / \mathrm{cm}^{2}$.

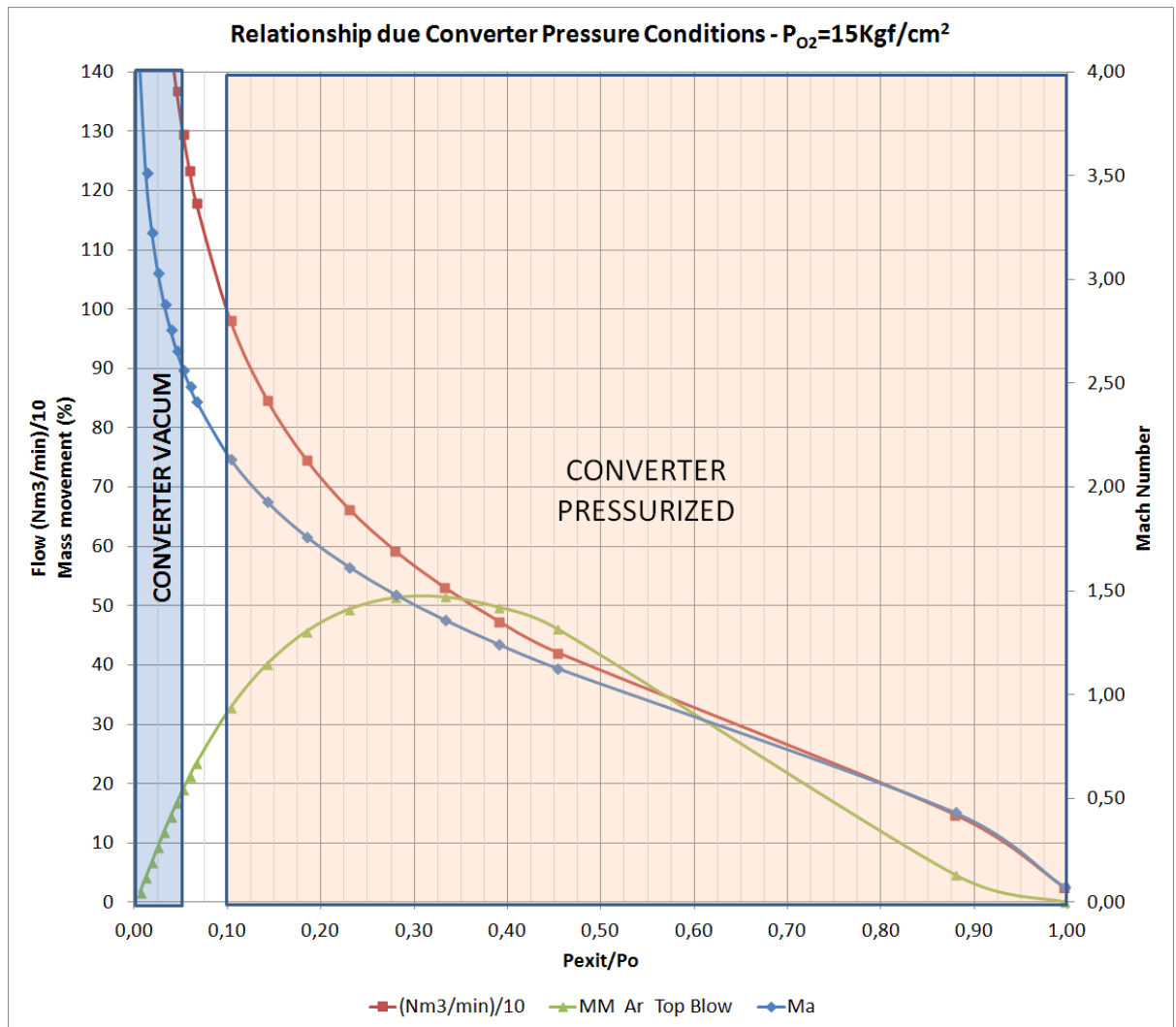

Figure 5 - Oxygen jet behaviour at $15 \mathrm{kgf} / \mathrm{cm}^{2} \times$ BOF internal pressures.

The pressure in the reservoir stagnant for fixed geometric conditions in the lance nozzles will be the determinant for the jet velocity, expressed by the Mach number. In turn, the Mach number will determine the kinetic energy dispatched in the lance nozzles. The increase in pressure in the stagnant reservoir then increases differential pressure with reflexes at the ambient pressure of the reference converter, expressed by the term "Po". In this way the jet properties are maximized under the low pressure conditions of the converter and in the vicinity of the equalization of the two pressures responsible for a sudden drop in these properties. The consequence of the high oxygen pressure is the increase of the kinetic energy reflecting on the mass of the liquid bath, however, close to the ends of the curve with the mass moving to zero, due to the degradation of the jet as a function of the ambient pressure of the converter. Comparisons were made with oxygen pressures equal to and lower than industrial practice as shown in Figures 6 to 7. 


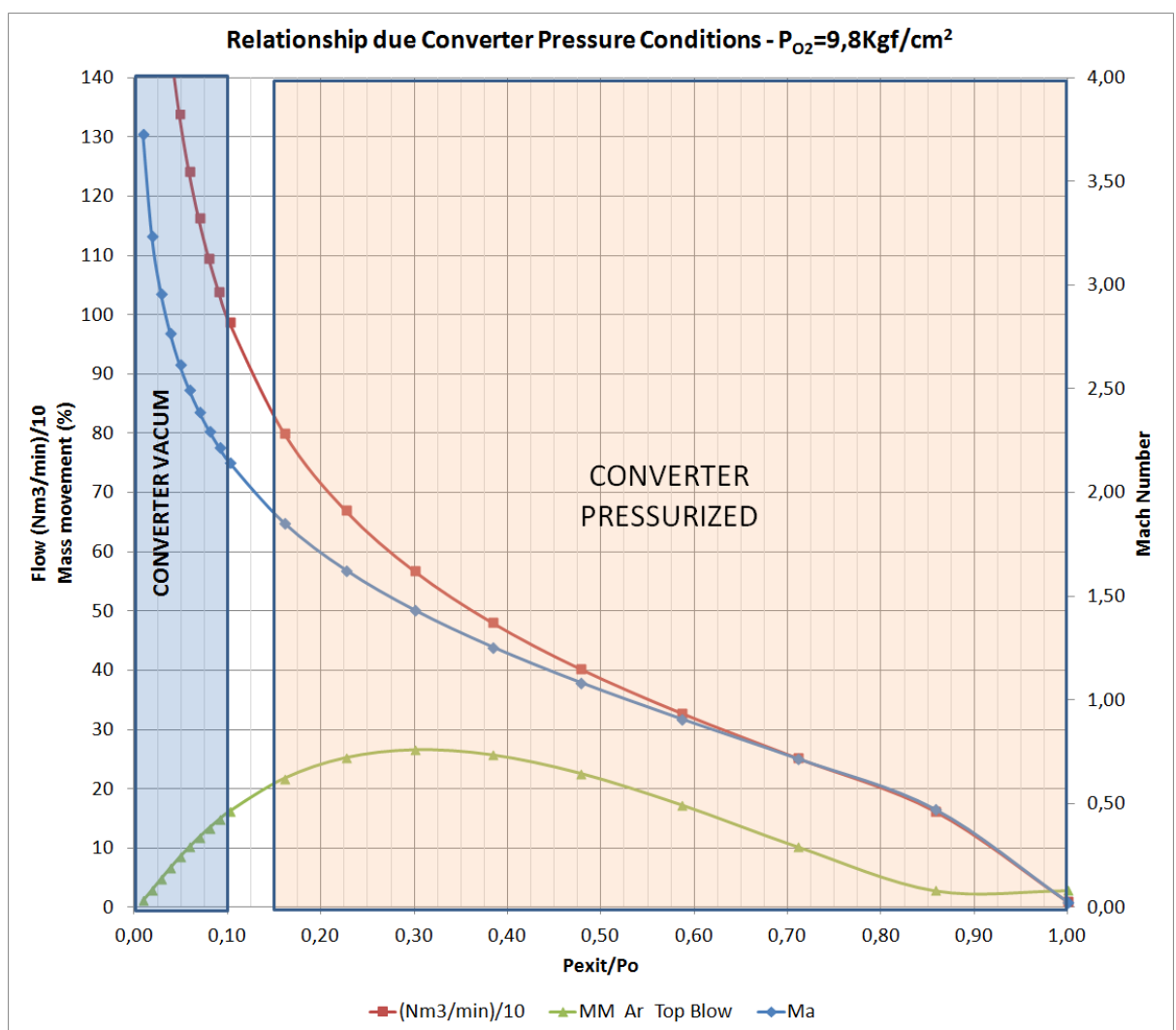

Figure 6 - Oxygen jet behaviour at $9.8 \mathrm{kgf} / \mathrm{cm}^{2} \times$ BOF internal pressures

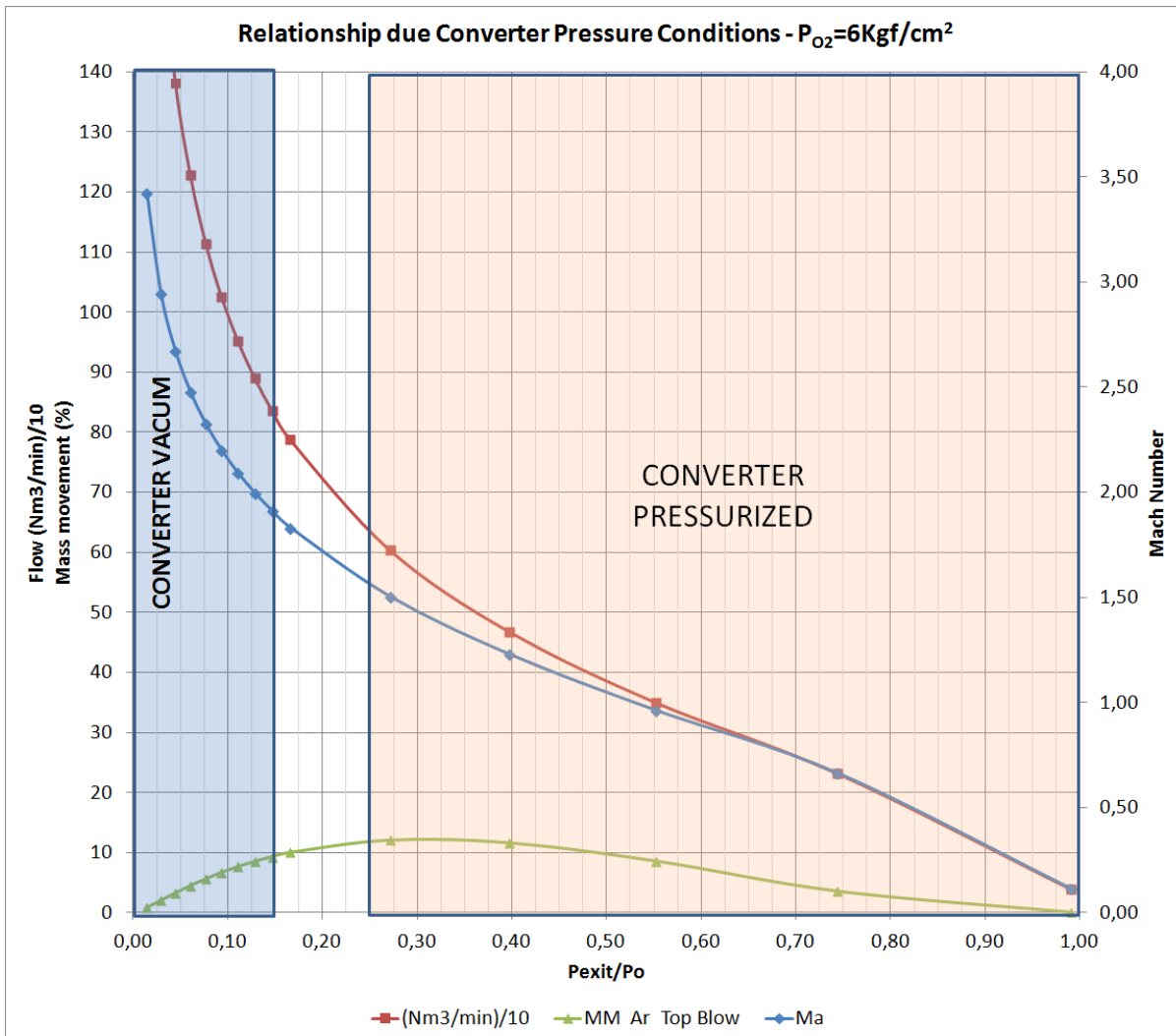

Figure 7 - Oxygen jet behaviour at $6.0 \mathrm{kgf} / \mathrm{cm}^{2}, x$ BOF internal pressures

In Figure 6 and Figure 7 the reduction in the pressure of the stagnant reservoir (oxygen pressure) reduces jet velocity in the nozzles, reducing the kinetic energy to 
be transferred to the bath with a direct impact in reducing the mass moved in the metallic bath. The Figure 7 shows that despite the influence of oxygen pressure on the flow of the oxygen jet and the amount of movement transferred to the bath, the behavior of the curves are similar. In all cases, the maximum moment transfer occurs in regions characterized by positive pressure inside the converters. Due to the oxygen pressure in the reservoir stagnant in relation to the pressure variation inside the converter, the region of pressures close to the environment undergoes gradual displacement with the reduction of the oxygen pressure. Another way to interpret is the relative ease of exhausts of the gas capture system, impose a negative pressure regime inside the converter if there is a drop in oxygen pressure. After this study, many real heats were investigated and below show a case.

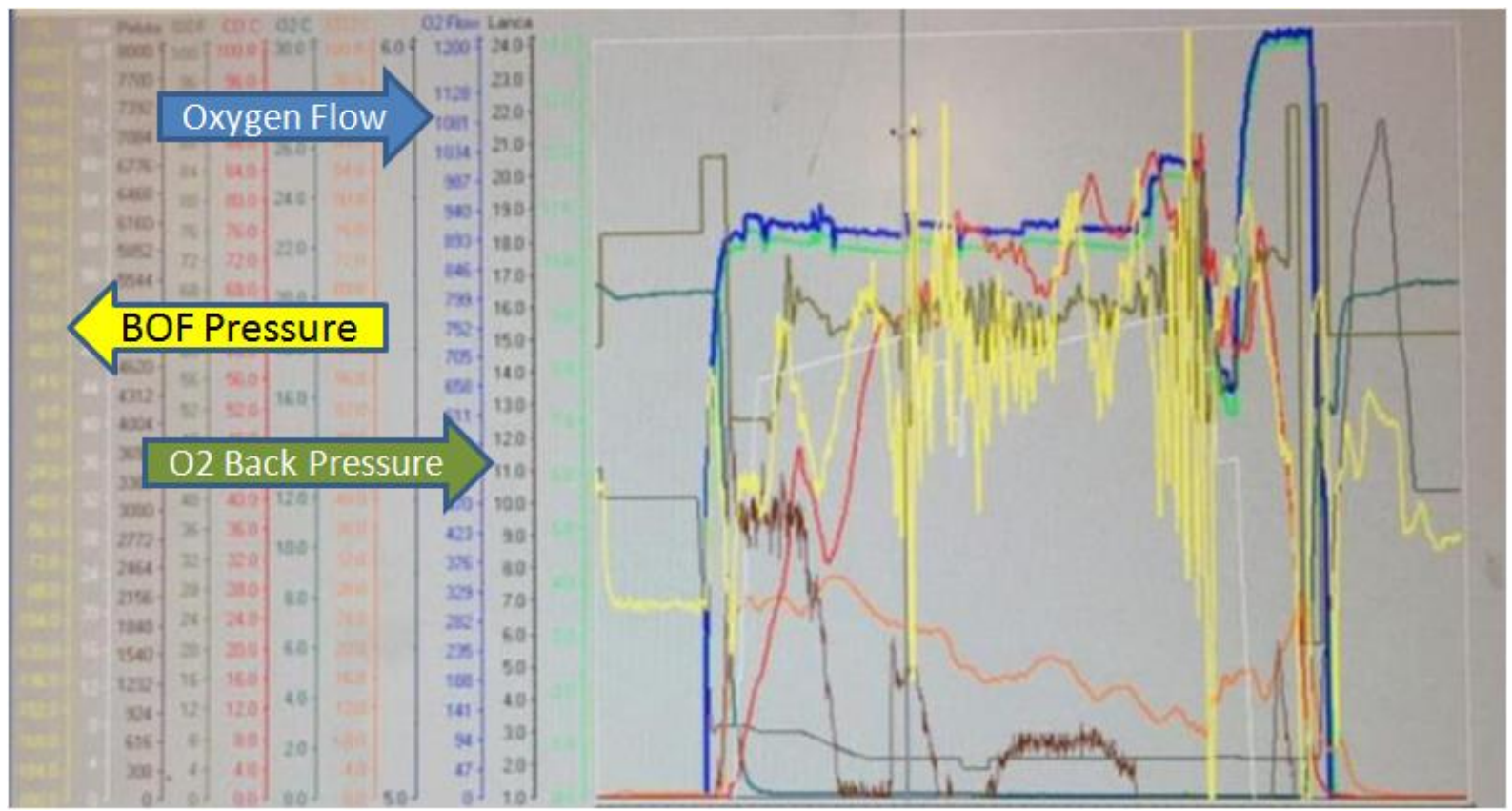

Figure 8 - Real Blow.

Figure 8 represents a heat and shows many trend lines. For this special study is important to see yellow lines that represents BOF pressure and it is strongly influenced by:

1. fan capacity or recovery gas control;

2. gap between converter mouth and movable skirt;

3. converter mouth conditions;

4. sources of gases additions from top bins like iron oxides and no burned materials (crude lime and dolomite materials);

5. tuyeres flow.

Oxygen flow (blue line) shows small variations but oxygen back pressure shows variations. The oxygen back pressure has a target to keep oxygen flow following the set point and after reach set point keep constant flow. Figure 9 shown to discuss case 1. 


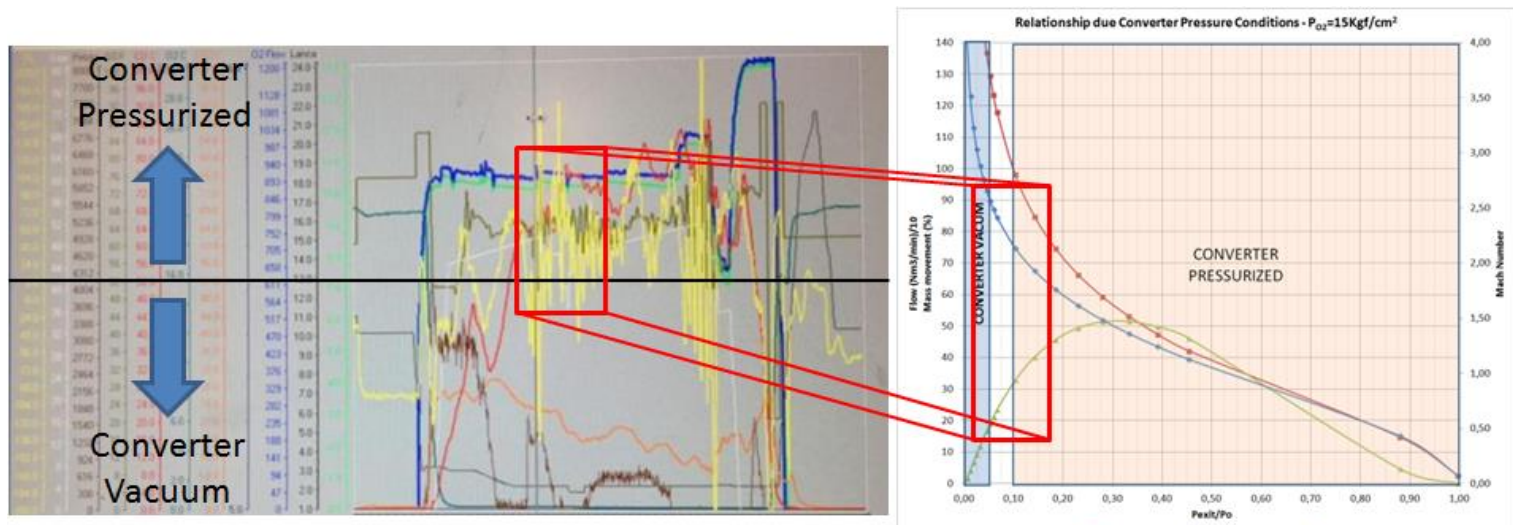

Figure 9 - Case 1: Decarburization time.

At figure 9, lance reaches decarburization time. In this stage oxygen flow tries to keep constant. BOF pressure (yellow line) oscillating between three pressures regions: converter pressurized, environmental pressures and vacuum conditions. These oscillations can be due additions from to bins or others gas source and fan controls to recovery gas. BOF pressure reflects your influence over back pressure, than over Mach number and mass movement is instable. Perhaps can be a reason for slopping and strongly damages at tip face.

Figure 10 shown situations near end blow to discuss.

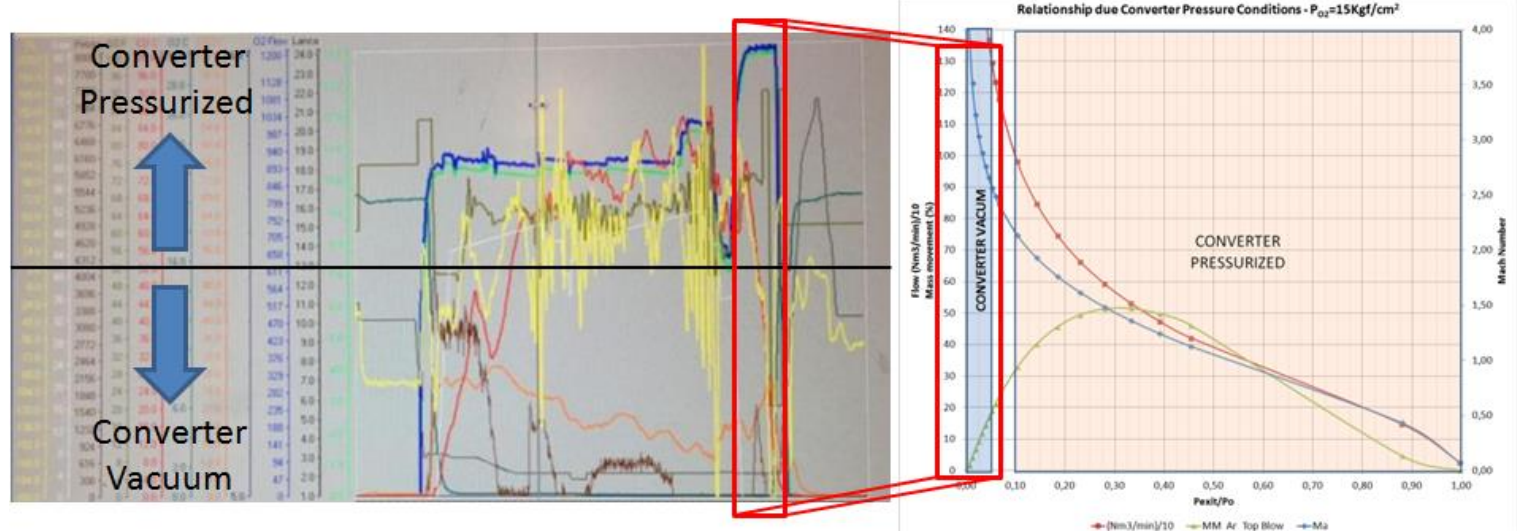

Figure 10 - Case 2: Near end blow.

At figure 10, to catch carbon after sub-lance, the oxygen flow was increase following set point. BOF pressure step by step was decreasing to compensate the increased flow crossing line to vacuum region. In this region, mass movement drops means less contact with oxygen and liquid bath and difficult to reach carbon targets.

\section{CONCLUSIONS}

The mainly conclusions are:

- Oxygen pressure has effects over mass movement for all pressure into converter;

- BOF pressure under vacuum region means low jet penetration and mass movement. Some behavior for very high BOF pressure;

- For best mass movement, converters need to work with little positive pressure. 


\section{Acknowledgments}

The authors thank UFMG and Lumar Metals for continuous support for research and development. They also thank Theodore J. Leczo and Raju PSJKK for the comments and language corrections. To Bruno Orlando de Almeida Santos, eternal friend.

\section{REFERENCES}

1 D. R. GLASS, G. C. SMITH, "Nozzle Theory. In: BOF Steelmaking," The Iron and Steel Society of the American Institute of Mining, Metallurgical and Petroleum Engineers, Volume three: Design. New York, Inc, 1976. Cap.8.

2 A. FERRI, "Elements of Aerodynamics of Supersonic Flows," The MacMillian Company New York:, 1949.

3 SZEKELY, J. THEMELIS, N. J., Rate Phenomena in Process Metallurgy. 1 ed. Montreal: John Wiley \& Sons, 1971. 784p.

4 MEIDANI, A. R. N., ISAC, M., RICHARDSON, A., CAMERON, A., GUTHRIE, R. I. L. Modeling Shrouded Supersonic Jets in Metallurgical Reactor Vessels. ISIJ International, 2004, v.44, n.10, p. 1639-1645.

5 ALAM, M., IRONS, G., BROOKS, G., FONTANA, A., NASER, J., Inclined Jetting and Splashing in Electric Arc Furnace Steelmaking. ISIJ International, 2011, v.51, n.9, p. 1439-1447.

6 ALAM, M., NASER, J., BROOKS, G., FONTANA, A. Computational Fluid Dynamics Modeling of Supersonic Coherent Jets for Electric Arc Furnace Steelmaking Process. Metallurgical and Materials Transactions B, volume 41B, p.1354-1367. Dec. 2010.

7 ALAM, M., NASER, J., BROOKS, G., FONTANA, A. Computational Fluid Dynamics Simulation of Supersonic Oxygen Jet Behavior at Steelmaking Temperature Metallurgical and Materials Transactions B, volume 41B, p.636645. Jun. 2010.

8 MAIA, B. T., Modelamento Físico e Matemático do Escoamento de Fluidos nos processos BOF e EOF. Belo Horizonte: Escola de Engenharia da UFMG, 2013. 238p. (Tese, Doutorado em Engenharia Metalúrgica).

9 MAIA, B. T., GARAJAU, F. S., GUERRA, M. S. L., CARVALHO, D. A. G., TAVARES, R. P. Efeito da Pressão Ambiente e da Temperatura do Oxigênio sobre a Penetração de Jato no Banho Metálico no BOF. In: SEMINÁRIO DE ACIARIA - INTERNACIONAL, 47., 2016, Rio de Janeiro. Anais eletrônicos. São Paulo: Associação Brasileira de Metalurgia, Materiais e Mineração, 2016. Disponível em: http://www.abmbrasil.com.br/anais. Acesso em: 03/10/2016. . 